\title{
Faktor yang Mempengaruhi Efisiensi Perbekalan Farmasi di Instalasi Bedah Sentral Rumah Sakit Umum Daerah Gambiran Kediri
}

\section{Factors Influencing Pharmaceutical Supply Efficiency in Central Surgical Installation of Gambiran District Public Hospital Kediri}

\author{
Evi Sa'adah ${ }^{1}$, Nurwulan Andadari ${ }^{1}$, Janik Kurniawati \\ ${ }^{1}$ Program Studi Magister Manajemen Rumah Sakit Fakultas Kedokteran Universitas Brawijaya Malang \\ ${ }^{2}$ Rumah Sakit Umum Daerah Gambiran Kediri
}

\begin{abstract}
ABSTRAK
Upaya efisiensi biaya mutlak harus dilakukan oleh setiap rumah sakit yang telah menyandang status Badan Layanan Umum Daerah (BLUD) serta menghadapi universal coverage. Penelitian ini bertujuan untuk mengetahui faktor-faktor yang mempengaruhi upaya efisiensi perbekalan farmasi di Instalasi Bedah Sentral (IBS) RSUD Gambiran Kota Kediri. Penelitian deskriptif kuantitatif menggunakan metode analisis faktor dilakukan pada seluruh (29 perawat) kamar operasi di RSUD Gambiran Kota Kediri. Instrumen penelitian menggunakan kuesioner yang dibuat berdasarkan analisis fishbone hasil wawancara mendalam dan observasi. Hasil penelitian menunjukkan faktor-faktor yang mempengaruhi upaya efisiensi perbekalan farmasi di IBS adalah pengetahuan terhadap SOP perbekalan farmasi, beban kerja, pengetahuan mengenai cost awareness, pencatatan, monitoring, evaluasi, pengisian kartu stok, penggantian stok yang terpakai, penyimpanan perbekalan farmasi, dan keterbatasan ruangan. Hasil analisis faktor menunjukkan variabel pembentuk faktor berpengaruh terbesar adalah variabel evaluasi persediaan perbekalan farmasi. Intervensi yang disarankan adalah optimalisasi floor stock dengan menempatkan petugas farmasi di IBS untuk memonitor dan mengevaluasi persediaan perbekalan farmasi di IBS sebagai bentuk inisiasi depo farmasi.
\end{abstract}

Kata Kunci: Efisiensi perbekalan, farmasi, instalasi bedah sentral

\begin{abstract}
Absolute cost efficiency efforts should be done by every hospital that has a status of Public Service Board as well as to deal with universal coverage. This study aims to determine the factors that affect the efficiency of pharmaceuticals supplies in the centralsurgical installation Gambiran district Public Hospital Kediri. This descriptive quantitative research used factor analysis method with total sampling of 29 surgery room nurses in Gambiran Regional Public Hospital Kediri. Research instrument was using questionnaires that were made based on fishbone analysis as a result of depth interviews and observation. The results shows that the factors affecting the efficiency of pharmaceutical suppliesare the knowledge of the pharmaceutical Standard Operating Procedure (SOP), work load, knowledge of cost awareness, recording, monitoring, evaluation, filling in stockcard, replacement of stock used, suppliesstorage, and room limitation. The result of the factor analysis shows that the variables forming the biggest influential factor is the evaluation variable of pharmaceutical supplies. Suggested intervention is floor stock optimizationby placing pharmacy personnelsto monitor and evaluate the pharmaceutical supplies as a form of pharmacy depotinitiation.
\end{abstract}

Keywords: Central Surgical Installation, costefficiency, pharmacy

Jurnal Kedokteran Brawijaya, Vol. 28, Suplemen No. 1, 2014: Evi Sa'adah. Program Studi Magister Manajemen Rumah Sakit Fakultas Kedokteran Universitas Brawijaya Malang, Jl. Veteran Malang 65142 Tel. (0341) 568989Email:evisa_ar@yahoo.com 


\section{PENDAHULUAN}

Rumah Sakit Umum Daerah (RSUD) Gambiran menjadi Badan Layanan Umum Daerah (BLUD) berdasarkan SK Walikota Kediri No. 89 Tahun 2009. Badan Layanan Umum Daerah memiliki karakteristik antara lain, yaitu: berkedudukan sebagai lembaga pemerintah yang tidak dipisahkan dari kekayaan negara; menghasilkan barang dana atau jasa yang diperlukan masyarakat; tidak bertujuan untuk mencari laba; dan dikelola secara otonom dengan prinsip efisiensi dan produktivitas ala korporasi (1). Prinsip efisiensi dan produktivitas ala korporasi inilah yang mendasari sebuah BLUD dalam hal ini RSUD Gambiran, untuk mampu melakukan efisiensi biaya menuju kemandirian rumah sakit.

Efisiensi biaya juga penting dilakukan rumah sakit guna menghadapi universal coverage pembiayaan kesehatan. Pada awal tahun 2014, Badan Penyelenggara Jaminan Sosial (BPSS) Kesehatan sebagai penyelenggara universal coverage akan mulai beroperasi. Pada era BPSS ini, pembayaran pelayanan kesehatan dilakukan menggunakan sistem paket yang mengacu pada tarif INACBGs. Perubahan sistem pembayaran fee for service menjadi sistem paket berdampak pada perubahan mindset, sistem, dan perilaku dalam mengelola rumah sakit dan melayani pasien. Menurut Thabrany, rumah sakit harus mampu melakukan efisiensi biaya dan perbaikan mutu yang terus-menerus agar dapat bertahan.

Efisiensi dapat didefinisikan sebagai perbandingan antara luaran (output) dengan masukan (input), atau jumlah luaran yang dihasilkan dari satu input yang dipergunakan. Menurut Mulyadi, efisiensi adalah tingkat pengendalian biaya atau pengorbanan sumber daya ekonomi yang diukur dalam satuan uang yang telah terjadi untuk mencapai tujuan yang telah ditetapkan (2). Menurut Cooper et al efisiensi biaya yang juga dikenal sebagai efisiensi ekonomis adalah rasio antara biaya minimum dengan biaya aktual. Jadi konsep yang digunakan dalam efisiensi ekonomis adalah meminimalkan biaya. Suatu proses produksi akan efisien secara ekonomis pada suatu tingkatan output apabila tidak ada proses lain yang dapat menghasilkan output serupa dengan biaya yang lebih murah $(3,4)$.

Faktor-faktor yang mempengaruhi efisiensi adalah motivasi, kemampuan kerja, suasana kerja, lingkungan kerja, perlengkapan dan fasilitas serta prosedur kerja. Motivasi dan kemampuan kerja terkait dengan sumber daya manusia, sedangkan suasana kerja, perlengkapan dan fasilitas serta prosedur kerja terkait dengan lingkungan kerja secara umum (5). Lingkungan meliputi lingkungan internal dan lingkungan eksternal. Lingkungan internal dan eksternal merupakan faktor-faktor yang membentuk, memperkuat atau memperlemah efektivitas pertanggungjawaban instansi atas wewenang dan tanggung jawab yang dilimpahkan kepadanya. Lingkungan internal termasuk budaya organisasi, perlengkapan dan fasilitas, serta prosedur kerja. Lingkungan eksternal adalah kekuatan yang timbul dari luar batas organisasi yang mempengaruhi keputusan serta tindakan di dalam organisasi seperti masyarakat dan peraturan pemerintah (6).

Upaya efisiensi biaya harus melibatkan unit karena komponen-komponen biaya tersebar di seluruh unit yang ada di rumah sakit. Seluruh unit di rumah sakit merupakan cost center. Cost Center adalah unit atau tempat dimana biaya-biaya langsung (direct cost) dipergunakan atau biaya yang terdapat pada unit-unit yang menghasilkan output atau produksi yang dapat dijual. Cost center diklasifikasikan menjadi unit penunjang dan unit produksi. Unit penunjang adalah unit-unit dalam struktur rumah sakit yang tidak menghasilkan pemasukan rumah sakit, namun terdapat sejumlah pengeluaran tertentu untuk operasionalisasi sehari-harinya. Unit produksi adalah unitunit yang menghasilkan pemasukan bagi rumah sakit dari pasien yang disebut juga sebagai revenue center (7).

Instalasi Bedah Sentral (IBS) adalah salah satu unit bisnis rumah sakit yang bertindak sebagai unit dengan pendapatan terbesar kedua setelah Instalasi Farmasi. Sebagai revenue center, IBS memiliki nilai Cost Recovery Rate (CRR) berkisar antara $84-89 \%$ pada Triwulan I tahun 2013. Nilai ini menunjukkan bahwa IBS sebagai revenue center belum dapat memberikan kontribusi profit bagi rumah sakit karena nilai belanja IBS masih lebih besar dari pendapatannya.

Apabila suatu unit bisnis di sebuah perusahaan merugi, maka pihak manajemen dapat saja memutuskan untuk dilakukan merger, akuisisi, atau likuidasi (8). Berbeda dengan rumah sakit yang terikat dengan Permenkes No. 340/Menkes/PER/III/2010 tentang klasifikasi rumah sakit. Berdasarkan Permenkes tersebut setiap rumah sakit harus memenuhi persyaratan jenis pelayanan, sumber daya manusia, peralatan, sarana dan prasarana, serta administrasi dan manajemen sesuai tipe rumah sakit yang disandangnya. Oleh karena itu, salah satu upaya yang harus dilakukan adalah efisiensi biaya guna mengurangi kerugian.

Biaya perbekalan farmasi di IBS merupakan salah satu komponen biaya yang seharusnya dapat dilakukan upaya efisiensi. Biaya ini menempati pos biaya terbesar kedua setelah jasa pelayanan sehingga apabila dapat dilakukan upaya efisiensi akan sangat berarti untuk menekan biaya operasional Instalasi Bedah Sentral. Penelitian ini bertujuan untuk mengetahui faktor-faktor yang mempengaruhi upaya efisiensi perbekalan farmasi di Instalasi Bedah Sentral (IBS) RSUD Gambiran Kota Kediri. Dengan mengetahui faktor-faktor berpengaruh, diharapkan dapat digunakan sebagai dasar kebijakan peningkatan upaya efisiensi perbekalan farmasi khususnya di IBS dan di RSUD Gambiran secara umum.

\section{METODE}

Studi ini merupakan penelitian deskriptif kuantitatif. Metode pengambilan data berupa wawancara, observasi dan kuesioner di IBS RSUD Gambiran Kota Kediri selama bulan Oktober hingga November 2013. Wawancara mendalam dan observasi langsung digunakan untuk memperoleh gambaran faktor-faktor berpengaruh yang kemudian dianalisis menggunakan diagram fishbone. Untuk mengetahui faktor yang paling berkontribusi dilakukan pengambilan data melalui kuesioner kepada semua perawat di IBS sejumlah 32 orang. Hasil kuesioner tersebut kemudian dianalisis menggunakan analisis faktor dengan software SPSS 20.

Skala pengukuran yang digunakan pada kuesioner ini adalah skala Likert. Skala Likert digunakan untuk menunjukkan perbedaan tingkat, perbedaan derajat, perbedaan jenjang maupun perbedaan kuantitas. Pilihan jawaban tersebut terdiri atas lima pilihan yaitu sangat sering, sering, kadang-kadang, hampir tidak pernah, dan 


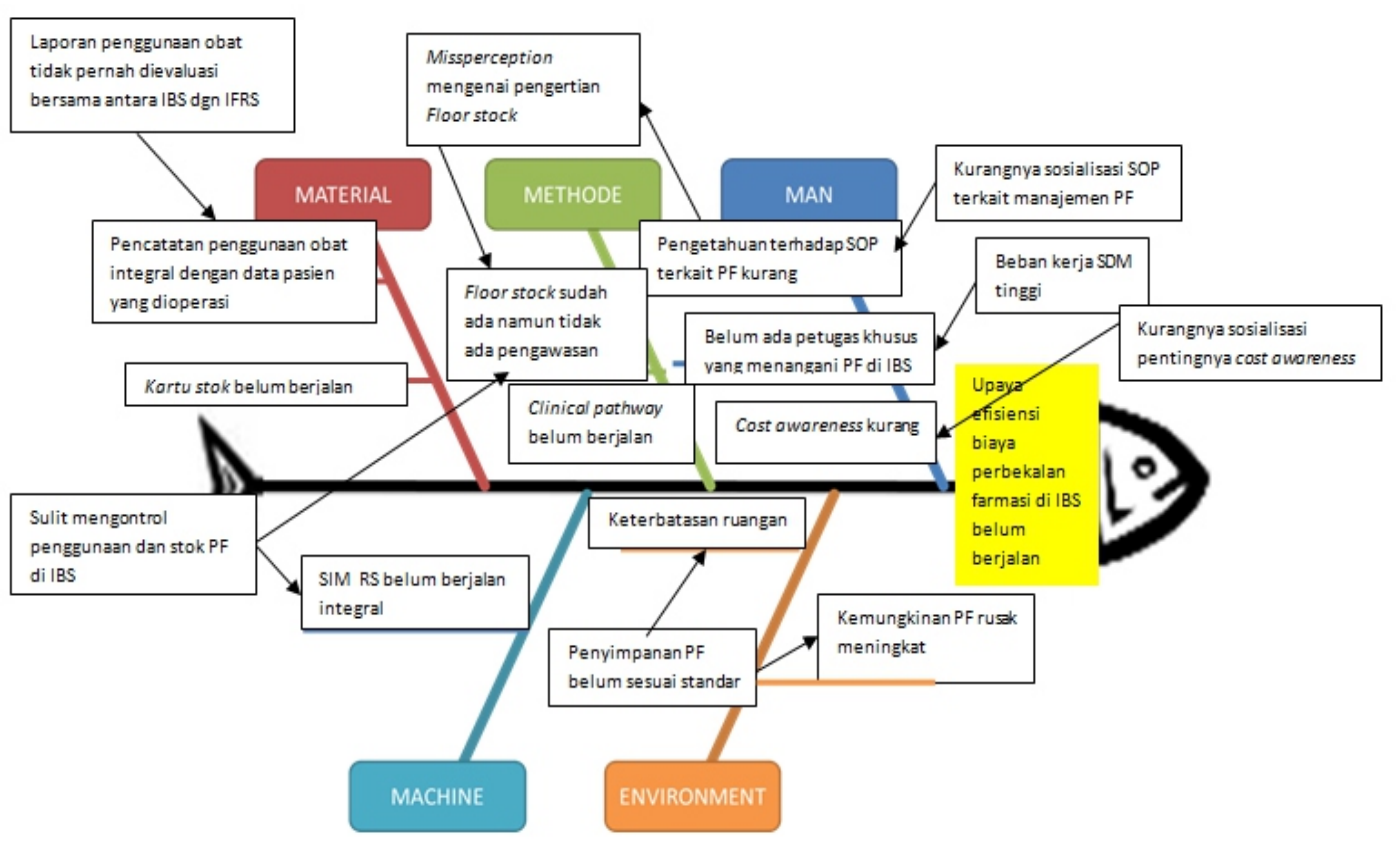

Gambar 1. Diagram fishbone faktor-faktor yang mempengaruhi upaya efisiensi perbekalan farmasi

tidak pernah $(9,10)$.

Variabel penelitian merupakan hasil analisis fishbone faktor-faktor yang mempengaruhi upaya efisiensi perbekalan farmasi di IBS yaitu pengetahuan terhadap Standar Operasional Prosedur (SOP) perbekalan farmasi, beban kerja, pengetahuan mengenai cost awareness, pencatatan, monitoring, evaluasi, pengisian kartu stok, penggantian stok yang terpakai, penyimpanan perbekalan farmasi, dan keterbatasan ruangan (Gambar 1).

Analisis data kuantitatif pada penelitian ini menggunakan analisis faktor dengan pendekatan eksplanatori. Analisis faktor ini digunakan untuk mengeksplorasi variabelvariabel yang telah ditentukan berdasarkan analisis fishbone. Salah satu tujuan analisis faktor adalah mereduksi jumlah variabel dengan cara mirip seperti pengelompokkan variabel (11). Pada analisis faktor dilakukan langkah-langkah: uji validitas dengan KaiserMeyer-Olkin (KMO) dan Bartlett's Test, uji kecukupan sampel dengan melihat nilai Measure of Sampling Adequacy (MSA), dan ekstraksi faktor untuk mendapatkan loading factor.

\section{HASIL}

\section{Karakteristik Responden}

Dari 32 kuesioner yang disebar kepada seluruh perawat di IBS, terdapat 3 kuesioner yang tidak kembali kepada peneliti sehingga jumlah sampel yang dianalisis adalah 29 sampel. Tabel 1 memperlihatkan bahwa seluruh responden (100\%) termasuk ke dalam kelompok usia produktif (15-44 tahun). Pada kelompok usia produktif ini proporsi terbanyak adalah usia antara 35-44 tahun (66\%). Jenis kelamin responden terbanyak adalah laki-laki (79\%), sedangkan sisanya adalah perempuan (14\%) dan tidak menjawab (7\%). Tingkat pendidikan responden mayoritas perguruan tinggi dengan persentase terbesar adalah D3/D4 (69\%) dan S1/Profesi (21\%). Hanya ada satu orang yang berpendidikan Sekolah Perawat Kesehatan (setara SMA). Dari Tabel 1 juga diketahui bahwa responden terbanyak telah bekerja selama lebih dari 10 tahun di IBS RSUD Gambiran (62\%).
Tabel 1. Karakteristik responden

\begin{tabular}{|c|c|c|c|}
\hline Karakteristik & Uraian & $\begin{array}{l}\text { Jumlah } \\
\text { (orang) }\end{array}$ & $\begin{array}{c}\text { Persentase } \\
\text { (\%) }\end{array}$ \\
\hline \multirow[t]{4}{*}{ Umur } & $<25$ tahun & 3 & 10 \\
\hline & $25-34$ tahun & 7 & 24 \\
\hline & $35-44$ tahun & 19 & 66 \\
\hline & $>45$ & 0 & 0 \\
\hline \multirow{3}{*}{$\begin{array}{l}\text { Jenis } \\
\text { Kelamin }\end{array}$} & Laki-laki & 23 & 79 \\
\hline & Perempuan & 4 & 14 \\
\hline & Abstain & 2 & 7 \\
\hline \multirow[t]{5}{*}{ Pendidikan } & SPK & 1 & 3 \\
\hline & D3/D4 & 20 & 69 \\
\hline & S1/Profesi & 6 & 21 \\
\hline & $\mathrm{S} 2$ & 0 & 0 \\
\hline & Abstain & 2 & 7 \\
\hline \multirow[t]{4}{*}{ Lama Bekerja } & $<1$ tahun & 0 & 0 \\
\hline & $<5$ tahun & 4 & 14 \\
\hline & $<10$ tahun & 7 & 24 \\
\hline & $>10$ tahun & 18 & 62 \\
\hline
\end{tabular}

Keterangan: Jumlah seluruh sampel $(n)=29$ orang

\section{Analisis Faktor}

Hasil uji reliabilitas terhadap 13 pertanyaan kuesioner yang mewakili faktor-faktor yang mempengaruhi upaya efisiensi perbekalan farmasi di IBS memberikan nilai alpha cronbach 0,885. Hal ini menunjukan bahwa semua pertanyaan kuesioner tersebut reliabel.

Analisis data untuk mengetahui faktor yang paling berpengaruh dilakukan dengan uji analisis faktor. Jumlah faktor yang dihasilkan ditetapkan sebanyak satu faktor yaitu faktor berpengaruh. Pada analisis faktor, uji validitas dilakukan dengan Kaiser-Meyer-Olkin (KMO) dan Bartlett's Test. Nilai KMO untuk korelasi antarvariabel yang diharapkan adalah lebih besar dari 0,5 dan signifikansi 
penelitian adalah 0,05. Dari hasil analisis diperoleh nilai KMO sebesar 0,882 yang artinya lebih besar dari 0,5. Sedangkan nilai $p$ dari Bartlett's Test of Sphericity sebesar 0,000 . Berdasarkan hasil tersebut berarti variabel dan sampel yang digunakan layak untuk dilakukan analisis lebih lanjut.

Korelasi antar variabel independen ditunjukkan oleh nilai MSA (Measure of Sampling Adequacy). Nilai MSA berkisar antara 0 hingga $1 . M S A=1$, variabel dapat diprediksi tanpa kesalahan oleh variabel yang lain, MSA $>0,5$ berarti variabel masih bisa diprediksi dan bisa dianalisis lebih lanjut dan MSA<0,5 berarti variabel tidak bisa diprediksi dan tidak bisa dianalisis lebih lanjut, atau dikeluarkan dari variabel lainnya. Variabel dengan nilai MSA kurang dari 0,5 kemudian dikeluarkan dari analisis. Variabel yang dikeluarkan yaitu beban kerja, pencatatan, dan penyimpanan perbekalan farmasi.

Pada variabel-variabel tersebut dilakukan ekstraksi dengan metode Principal Component Analysis (PCA). Apabila nilai PCA pada variabel lebih besar daripada nilai koefisien 0,5 berarti variabel tersebut mewakili faktor yang terbentuk. Ekstraksi faktor menghasilkan satu faktor yang terdiri atas variabel-variabel yang berpengaruh terhadap upaya efisiensi seperti yang ditunjukkan oleh Tabel 2. Tiga variabel berpengaruh yang memiliki nilai PCA terbesar berdasarkan analisis di atas yaitu evaluasi persediaan perbekalan farmasi yang belum berjalan, kurangnya pengetahuan mengenai SOP pengadaan perbekalan farmasi dari Gudang atau Depo dan kurangnya pengetahuan mengenai kesadaran petugas terhadap pentingnya efisiensi biaya operasional (cost awareness).

\section{Tabel 2. Komponen matriks hasil analisis faktor}

\begin{tabular}{lr}
\hline \multicolumn{1}{c}{ Variabel } & Nilai \\
\hline PCA &, 949 \\
\hline Evaluasi persediaan perbekalan farmasi &, 871 \\
Pengetahuan mengenai SOP pengadaan perbekalan farmasi &, 862 \\
dari Gudang/Depo &, 857 \\
Pengetahuan mengenai cost awareness &, 829 \\
Pengetahuan mengenai SOP penyimpanan perbekalan farmasi &, 814 \\
Monitoring persediaan perbekalan farmasi &, 786 \\
Pengisian kartu stok &, 695 \\
Pengetahuan mengenai SOP floor stock &, 631 \\
Pengetahuan mengenai SOP pemakaian perbekalan farmasi &, 498 \\
\hline Pengisian kembali stok yang ada & Keterbatasan ruangan penyimpanan perbekalan farmasi
\end{tabular}

Keterangan: $\mathrm{SOP}=$ Standart Operating Procedure

\section{DISKUSI}

\section{Karakteristik Responden}

Telah dilakukan analisis univariat untuk mengetahui karakteristik responden berupa umur, jenis kelamin, pendidikan, dan lama bekerja. Pada penelitian ini belum dilakukan analisis lebih lanjut baik bivariat maupun multivariat untuk melihat hubungan dan pengaruh karakteristik responden terhadap upaya efisiensi perbekalan farmasi di IBS. Penelitian yang dilakukan Aprilian menunjukkan bahwa umur responden tidak berpengaruh terhadap tingkat efisiensi karyawan dalam memproduksi barang atau jasa, sedangkan lama bekerja berpengaruh pada tingkat efisiensi karyawan (12).

Berbeda dengan Aprilian, Spector menyatakan bahwa karyawan dengan usia yang lebih tua memiliki tingkat kepuasan kerja yang lebih tinggi dibandingkan karyawan dengan usia yang lebih muda. Hal ini dikarenakan pada karyawan yang telah berusia lebih tua telah merasa lebih nyaman dan toleran terhadap tupoksi pekerjaannyaserta belajar untuk menurunkan harapannya (13). Hal ini cukup sejalan dengan hasil pengamatan di lapangan yang menunjukkan bahwa perawat IBS yang lebih tua dan memiliki pengalaman bekerja lebih lama memiliki kecenderungan tidak peduli terhadap upaya efisiensi. Berdasarkan pengalaman mereka selama bekerja, tidak ada pengaruh atau konsekuensi apapun atas kepedulian mereka terhadap upaya efisiensi selama mereka dapat menjalankan fungsi utamanya sebagai perawat IBS dengan baik sehingga mereka pun berusaha untuk cukup merasa puas dengan kondisi yang ada.

Penelitian yang dilakukan Muath dan Mohammed membuktikan bahwa perempuan memiliki tingkat kepuasan kerja dan komitmen berorganisasi lebih tinggi dari laki-laki, sedangkan karyawan dengan tingkat pendidikan yang semakin tinggi menunjukkan tingkat kepuasan kerja dan komitmen berorganisasi yang menurun (13). Berdasarkan pengamatan, IBS dengan mayoritas perawat adalah laki-laki menunjukkan kurangnya komitmen berorganisasi terutama dalam hal administratif berupa pencatatan dan pelaporan yang belum berjalan optimal. Tingkat pendidikan yang hampir merata di IBS yaitu pendidikan diploma atau setingkat perguruan tinggi menunjukkan bahwa perawat di IBS telah memiliki pengetahuan yang baik dalam bidang keperawatan. Hal ini diharapkan dapat menjadi faktor pendukung terlaksananya optimalisasi upaya efisiensi perbekalan farmasi agar penggunaan obat, Bahan Hasil Pakai (BHP), dan alkes dapat lebih efisien. Program pelatihan dan sosialisasi sangat diperlukan sebagai sarana penunjang terlaksananya optimalisasi upaya efisiensi tersebut.

\section{Optimalisasi Floor Stock di Instalasi Bedah Sentral}

Analisis faktor menghasilkan variabel evaluasi persediaan perbekalan farmasi sebagai variabel yang paling berpengaruh terhadap upaya efisiensi perbekalan farmasi di IBS dibanding variabel lainnya. Cronbach menyatakan bahwa evaluasi merupakan pemeriksaan yang sistematis terhadap segala peristiwa yang terjadi sebagai akibat dilaksanakannya suatu program (14). Selama ini persediaan perbekalan farmasi di IBS belum pernah dilakukan evaluasi berupa stock opname. Alasan yang dikemukakan oleh kepala ruangan IBS bahwa persediaan yang ada hanya sedikit jumlahnya. Sesuai SOP RSUD Gambiran yang tertuang dalam Instruksi Kerja Pengendalian floor stock di ruangan/poli/instalasi terkait, definisi floor stock adalah suatu proses kegiatan penyediaan perbekalan farmasi terutama obat-obat emergensi, strategis, dan bahan habis pakai. Stock opname dilakukan sebagai bentuk pengendalian floor stock yaitu upaya pengendalian ketersediaan dan ketetapan jumlah barang floor stock sesuai dengan jenis dan jumlah yang tercantum di buku serah terima barang floor stock kepada ruangan melalui suatu kegiatan stock opname. Banyak sedikitnya persediaan perbekalan farmasi di ruangan 
disesuaikan dengan kebutuhan yang kemudian disepakati antara ruangan dengan Instalasi Farmasi Rumah Sakit. Stock opname penting untuk dilakukan agar persediaan yang ada tidak dianggap stock out yang berakibat tidak terhitung dalam inventaris Instalasi Farmasi.

Penelitian yang dilakukan oleh Amanda menunjukkan bahwa tingkat perputaran obat-obatan yang tinggi menyebabkan diperlukannya pengelolaan, pengawasan dan pengendalian yang baik terhadap persediaan obatobatan. Tujuannya adalah untuk menjaga persediaan obat-obatan dari resiko kehilangan dan kerusakan, memeriksa ketelitian dan kebenaran data akuntansinya, meningkatkan efisiensi, menghindari terjadinya kesalahan-kesalahan dan penyimpangan-penyimpangan yang mungkin terjadi yang dapat merugikan rumah sakit (15). Penelitian yang dilakukan oleh Syamas pun menyatakan bahwa penggunaan obat anastesi dan alat kesehatan habis pakai di Instalasi Bedah RSUD Purbalingga belum efisien akibat tidak adanya sistem pencatatan dan pelaporan yang baku (16).

Penelitian yang dilakukan oleh Surbayati menunjukkan bahwa masalah pada sistem floor stock meliputi terjadinya kekosongan obat, sistem floor stock yang tidak efektif dan efisien, sistem pelaporan dan penggunaan floor stock yang kurang baik juga terjadi di ICCU RSUD Dr. Zainoel Abidin Banda Aceh. Penelitian ini menghasilkan satu kesepakatan bersama berupa alur permintaan floor stock, pengurangan item floor stock, serta formulir yang digunakan untuk permintaan dan pemantauan floor stock di ICCU. Hal ini bertujuan agar pengelolaan suplai akan menjadi lebih mudah (17).

Selama ini petugas di IBS merasa beban kerja yang tinggi mengakibatkan mereka kesulitan mengatur floor stock yang ada. Pencatatan penggunaan obat dan alkes yang digunakan selama tindakan dilakukan setelah tindakan

\section{DAFTAR PUSTAKA}

1. Kasih DPD, Sudarsono, Suhariningsih, dan Ridwan M. Eksistensi Badan Layanan Umum (BLU) dalam Penyelenggaraan Fungsi Pemerintah. [Disertasi]. Universitas Brawijaya, Malang. 2013.

2. Mulyadi. Akuntansi Biaya. Edisi 5. Yogyakarta: Aditya Media; 2000.

3. Anandra AR. Analisis Efisiensi Penggunaan Faktorfaktor Produksi pada Usaha Ternak Ayam Ras Pedaging di Kabupaten Magelang. [Skripsi]. Universitas Diponegoro, Semarang. 2010.

4. Marathe S. Benchmarking Community Health Centers' Efficiency: Multivariate Analysis. [Dissertation]. University of Central Florida, Orlando. 2006.

5. Yuspita RF. Efisiensi dan Efektivitas dalam Birokrasi. [Tesis]. Universitas Jenderal Soedirman, Purwokerto. 2012.

6. Adisasmita R. Manajemen Pemerintah Daerah. Edisi 1. Yogyakarta: Graha Ilmu; 2011.

7. Suryana A. Aplikasi Simulasi Biaya Operasional Rumah Sakit Umum Daerah di Propinsi Lampung dengan Metode Double Distribution dalam Upaya Membantu Menyiapkan Pola Tarif Pelayanan Rumah Sakit Swadana yang Terjangkau oleh Masyarakat. operasi. Sebelumnya petugas mengambil obat dan alkes dari floor stock baru kemudian meresepkan obat dan alkes yang telah digunakan untuk mengganti floor stock yang terpakai. Kemungkinan perawat lupa melakukan pencatatan sangat mungkin terjadi, terutama pada harihari ketika sedang banyak pasien yang dioperasi.

Penempatan petugas farmasi yang terjun langsung ke IBS untuk melakukan monitoring penggunaan obat setiap haridan evaluasi berupa stock opname yang rutin setiap seminggu sekali adalah bentuk intervensi optimalisasi floor stock dalam upaya efisiensi perbekalan farmasi. Penempatan petugas ini merupakan inisiasi pembentukan depo farmasi di IBS yang sementara ini belum dapat diwujudkan dikarenakan keterbatasan ruangan yang ada.

Penelitian ini menunjukkan bahwa belum optimalnya proses monitoring dan evaluasi floor stock menjadi faktor paling berkontribusi pada upaya efisiensi biaya perbekalan farmasi di IBS RSUD Gambiran Kota Kediri. Optimalisasi dilakukan dengan membuat program inisiasi depo farmasi berupa penempatan petugas farmasi yang terjun langsung ke IBS untuk melakukan monitoring penggunaan obat di IBS setiap hari dan melakukan evaluasi berupa stock opname seminggu sekali.

Pada penelitian ini responden yang digunakan hanya perawat di IBS, belum melibatkan petugas IBS lainnya misalnya dokter dan tenaga administrasi sehingga yang tergambarkan baru sebatas upaya efisiensi perbekalan farmasi yang dilakukan oleh perawat. Disamping perawat dokter merupakan pelaksana utama pelayanan di IBS yang juga berperan dalam efisiensi biaya. Meskipun demikian pengelolaan IBS terutama dalam manajemen perbekalan lebih banyak dikelola oleh perawat. Uji yang dilakukan baru sebatas analisis faktor sehingga diperlukan uji lebih lanjut berupa uji korelasi untuk mengetahui kekuatan hubungan faktor determinan efisiensi biaya farmasi di IBS.

Seminar Nasional Aplikasi Teknologi Informasi. Yogyakarta, 17 Juni 2006.

8. Kusmargiani IS. Analisis Efisiensi Operasional dan Efisiensi Profitabilitas pada Bank yang Merger dan Akuisisi di Indonesia. [Tesis]. Universitas Diponegoro, Semarang. 2006

9. Yani A. Hubungan Sistem Paket Obat Habis Pakai terhadap Efisiensi Biaya Tindakan Operasi Sectio Caesarea di RSUD Sungai Penuh Kabupaten Dati II Kerinci Propinsi Jambi Tahun 2000. [Tesis]. Universitas Sumatera Utara, Medan. 2000.

10. Fahruzy K. Hubungan Kepuasan Kerja dengan Kinerja Pegawai Negeri Sipil di Kantor Camat Pontianak Kota. Governance. 2012; 1(1).

11. Solimun. Structural Equation Modeling dan Lisrel. Malang: Fakultas MIPA Universitas Brawijaya; 2005.

12. Aprilian T. Analisis Produktivitas Tenaga Kerja pada Pekerjaan Struktur Rangka Atap Baja (Studi Kasus Proyek Pembangunan Rumah Sakit Dr. Moewardi Surakarta Jawa Tengah). [Tesis]. Universitas Sebelas Maret, Surakarta. 2010.

13. Muath E and Mohammed F. The Impact of Gender, Age, Years of Experience, Education Level, and Position Type on Job Satisfaction and Organizational Commitment: An Exploratory Study in the Kingdom of 
Bahrain. International Journal of Business and Social Science. 2013;4(11): 108-119.

14. Wulan AR. Pengertian dan Esensi Konsep Evaluasi, Asesmen, Tes, dan Pengukuran. [Skripsi]. Universitas Pendidikan Indonesia, Bandung. 2004.

15. Amanda El. Evaluasi Pelaksanaan Sistem dan Prosedur Akuntansi Persediaan Obat-obatan. [Skripsi]. Universitas Pembangunan Nasional
Veteran, Yogyakarta. 2010.

16. Syamas R. Analisis Biaya Pemakaian Obat dan Alat Kesehatan Habis Pakai di Instalasi Bedah RSUD Purbalingga. [Tesis]. Universitas Gadjah Mada, Yogyakarta. 2000.

17. Surbayati E dan Suryawati S. Upaya Pengembangan Pedoman Sistem Floor Stock di ICCU RSUD Dr. Zainoel Abidin Banda Aceh. [Tesis]. Universitas Gajah Mada, Yogyakarta. 2009. 